\title{
Genistein elicits its anticancer effects through up-regulation of E-Cadherin in Acute Lymphoblastic Leukemia (ALL) cells: an in vitro experimental study
}

\author{
Vahideh Namordizadeh ${ }^{1}$, Kianoosh Malekzadeh ${ }^{1,2}$, Sohaila Ebrahimi ${ }^{1}$
}

\begin{abstract}
${ }^{1}$ Molecular Medicine Research Center, Hormozgan Health Institute, Hormozgan University of Medical Sciences, Bandar Abbas, Iran

${ }^{3}$ Ph.D., Department of Medical Genetics, Faculty of Medicine, Hormozgan University of Medical Sciences, Bandar Abbas, Iran
\end{abstract}

\section{Type of article: Original}

\begin{abstract}
Background and aim: Genistein is an isoflavone that acts as a potent inhibitor of tyrosine kinase in several cancers. The aim of this study was to elucidate the impact of genistein on leukemia cell lines through E-cadherin signaling pathway.

Methods: This study was conducted in 2016 at the Molecular Medicine Research Center (Hormozgan University of Medical Sciences, Bandar Abbas, Iran). In this in vitro experimental study, the Acute leukemia lymphoma (ALL) cell lines MOLT4 (as mild acute lymphoblastic leukemia cell line) and JURKAT (as high aggressive acute lymphoblastic leukemia cell line) were cultured and then treated with different concentrations of genistein (10, $25,40$ and $55 \mu \mathrm{M})$ for 24,48 and 72 hours. Its cytotoxicity and anti-cancer properties on ALL cell lines were evaluated by calculating the growth rate and MTT assay. Eventually, the effect of genistein on the expression level of E-cadherin was examined using a quantitative Real-Time PCR. In the present research, we used in vitro experimental study.

Results: The percentage of vital malignant cells treated with genistein in comparison with non-treated cells was significantly decreased $(\mathrm{p}<0.03)$. E-cadherin expression was significantly $(\mathrm{p}<0.02)$ up-regulated between 2 to 4 times as compared with non-treated ones. Even though it seems that genistein induces its anti-cancer properties on all doses, it was found that there is a negative correlation between these anti-cancer properties and increasing the concentration and exposure time of genistein.

Conclusion: The present findings suggest that genistein possesses a growth inhibitory effect on ALL similar to solid tumor cells. It can also be deduced that genistein could be considered as a natural agent to potentially control the invasion of malignant cells and expedition of disease, which is promising and fascinating. From increasing the expression of E-cadherin as a tumor suppressor gene, what it is pioneering in reporting is another mechanism of action of genistein.
\end{abstract}

Keywords: Cell lymphoblastic leukemia-lymphoma; Cadherins; Genistein

\section{Introduction}

Acute leukemia lymphoma (ALL) has been universally fatal for the past fifty years (1). ALL includes a heterogeneous group of malignant lymphoid disorders with different biological and clinical features (2). ALL prognosis and therapy is based on age, immunophenotype, karyotype, and predicted risk of central nervous system involvement (3). Substantial advances have been made in the past five decades in the treatment of ALL patients (4).

\section{Corresponding author:}

Dr. Kianoosh Malekzadeh, Molecular Medicine Research Center, Hormozgan Health Institute, Hormozgan University of Medical Sciences, Bandar Abbas, Iran.

Tel: +98.9176108396, Fax:+98.7633354939, Email: keyanoosh@gmail.com

Received: January 10, 2018, Accepted: June 12, 2018, Published: March 01, 2019

iThenticate screening: June 12, 2018, English editing: December 19, 2018, Quality control: December 19, 2018

This article has been reviewed / commented by six experts

Funding: Research Vice Chancellor of Hormozgan University of Medical Science (Project no: 9380)

Ethics approval: HUMS.REC.1394.134 (Hormozgan University of Medical Sciences)

(C) 2019 The Authors. This is an open access article under the terms of the Creative Commons Attribution-NonCommercialNoDerivs License, which permits use and distribution in any medium, provided the original work is properly cited, the use is non-commercial and no modifications or adaptations are made. 
Genistein is a potent inhibitor of tyrosine kinase, which is involved in proliferation signal cascades of cell growth (5) but with no effect on threonine and serine kinases (6). Moderate doses of genistein have been found to have inhibitory effects on the prostate, cervix, brain, breast, and colon cancers (7). Genistein has therapeutic effects on ALL (8), and has been suggested as an alternative compound. Several studies have been performed to elicit the anticancer mechanism against cancer cells over last decade, (9) particularly, association between dietary flavonoids such as genistein and infant leukemia (10). Hence, genistein could be a suggestive substance in the treatment of ALL. There are reports that genistein acts through inhibition of mTOR pathway and blocking of protein synthesis in ALL cell lines (9).

E-cadherin is a cell-cell adhesion molecule, transmembrane glycoprotein $120-\mathrm{kDa}(11,12)$ involved in facilitating cell-cell adhesion between nearby epithelial cells in different tissues $(12,13)$. This glycoprotein is thought to play a significant role in trophoblastic differentiation. Cellular adhesiveness may be a critical step in the ability of epithelial tumor cells to invade and metastasize both in vitro and in animal model systems (12). Due to the novelty of the present study and the lack of similar research in this subject, the aim of this study has been to investigate the effects of genistein on the invasive potential of the human carcinoma cell line ALL. Based on our best knowledge and findings from web research, there is no documented investigation to evaluate the effect of genistein on ALL or ECadherin. For exploring its underlying mechanism, this program examined the role of E-cadherin signaling pathway in the inhibitory effects of genistein on ALL cell invasion.

\section{Material and Methods}

\subsection{Cell line}

This in vitro experimental study was carried out in 2016 at the Molecular Medicine Research Center, Hormozgan University of Medical Sciences, Bandar Abbas, Iran. The cell lines used in this study were MOLT4 and JURKAT purchased from the Pasteur Institute of Iran. ALL cell lines were cultured in RPMI and L-Glutamine medium supplemented with 10\% fetal bovine serum (FBS) and 500 $\mu$ antibiotics (penicillin) in a humidified incubator at 37 ${ }^{\circ} \mathrm{C}$ with $5 \% \mathrm{CO} 2$. The number of cells counted after the second passage. Then cell viability was determined by using Neobar Lam and Trypan blue techniques, respectively. The plates that had cell viability of more than $95 \%$ were used. ALL cell lines were treated with $10 \mu \mathrm{M}, 25 \mu \mathrm{M}, 40 \mu \mathrm{M}$ and $55 \mu \mathrm{M}$ genistein (Sigma-Aldrich, USA). Treated cells were harvested after 24, 48 and 72 hours for further molecular assays.

\subsection{MTT assay (Thiazolyl Blue Tetrazolium Bromide)}

MTT assay was used to investigate the effects of genistein on cellular proliferation. To do this, $5 \times 10^{5}$ cells were seeded in 96-well plates and incubation for 3-4 hours was done. Then, our cells were treated in various concentrations of genistein $(10,25,40$, and $55 \mu \mathrm{M} / \mathrm{L})$. Furthermore, untreated cells were considered as a negative control. Then the MTT survival assay was done across the different time periods (24, 48, and 72 hours). According to the conversion of tetrazolium dye (MTT) to a blue formazan product, cell viability was predicted by a colorimetric analysis. The absorbance of cell lysates in DMSO solution was read by ELISA Reader (Anthos 2020; England) at $495 \mathrm{\eta m}$.

\subsection{RNA extraction}

The total RNA was extracted from cells using an RNeasy Plus mini kit (QIAGEN, Germany) according to the manufacturer's protocol. The extracted RNA was quantified by running on $1.5 \%$ agarose gel electrophoresis. The $18 \mathrm{~S}$ and 28S RNA bands should be visualized under a transillumiator (Figure 1). The yield was quantified spectrophotometrically at 260 and $280 \eta \mathrm{m}$ by NanoDrop 1000 (Thermo, USA). The proportion of 2.0 obtained from $260 / 280$ indicates the quality of extracted RNA.

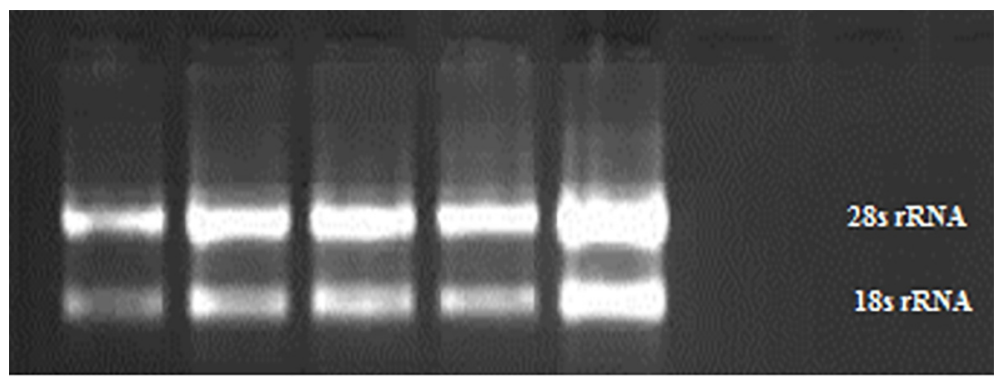

Figure 1. Extracted RNA electrophoresis. 


\section{4. cDNA synthesis and quantitative Real-Time PCR}

The total RNA $(2 \mu \mathrm{g})$ was reversely transcribed to cDNA using RevertAid TM First Strand cDNA Synthesis Kit (Cat. No.1632, Fermentas, Canada), by applying random hexamer primer following the manufacturer's protocol. Quantitative RT-PCR was conducted on a Real-time PCR (Corbett, Rotor-Gene 6000, Australia) and Sybr GreenMaster Mix (Takara Cat No \# RR820S \#RR820Q, Japan) according to the manufacturer's instructions. All reactions were carried out in $20 \mu \mathrm{L}$ of the mixture containing $2 \mu \mathrm{L}$ of cDNA, Master mix $2 \mathrm{X}$, ROX dye $50 \mathrm{X}$ and 10 pmol of each primer pair for E-cadherin and $\beta$-actin. The thermal cycling status was an initial denaturation at $95{ }^{\circ} \mathrm{C}$ for $30 \mathrm{~s}$ followed by 4 cycles of denaturation at $94{ }^{\circ} \mathrm{C}$ for $5 \mathrm{~s}$, annealing at temperatures for each primer pair for $15 \mathrm{~s}$ and an elongation at $60{ }^{\circ} \mathrm{C}$ for 30s. Expression levels of E-cadherin were normalized by $\beta$-actin expression as the housekeeping gene and calculated through the $2^{-\Delta \Delta \mathrm{CT}}$ method. The sequence of specific primer sets for each gene, amplicon sizes and annealing temperature of the primers used for Real- time PCR time are displayed in Table 1.

Table 1. Primers designed for amplification of E-cadherin and $\beta$-actin

\begin{tabular}{|l|l|l|l|}
\hline Gene & Primer $\left(5^{\prime} \rightarrow 3^{\prime}\right)$ & Amplicon Size $(\mathrm{bp})$ & $\operatorname{Tm}\left({ }^{\circ} \mathrm{C}\right)$ \\
\hline E-cadherin & $\begin{array}{l}\text { F: GAGAAGAGGACCAGGACTT } \\
\text { R: CACGAGCAGAGAATCATAAG }\end{array}$ & 216 & 59 \\
\hline$\beta$-actin & $\begin{array}{l}\text { F: GCCTTTGCCGATCCGC } \\
\text { R: GCCGTAGCCGTTGTCG }\end{array}$ & 90 & 58 \\
\hline
\end{tabular}

\subsection{Statistical analysis}

Statistical analysis was performed using IBM@ SPSS $\odot$ Statistics version 21 (IBM@ Corp., Armonk, NY, USA), Microsoft Excel and Prism-5 software, and p-values less than 0.05 were considered statistically significant in our experiments. In addition, for investigating the expression pattern of target gene, Spearman's Rank-Order Correlation and Mann-Whitney U tests were used.

\subsection{Ethical approval}

This article does not contain any studies with human participants or animals by any of the authors. For this type of study, formal consent is not required. The ethics committee of Hormozgan University of Medical Sciences approved the ethics of this research (ref. no.: HUMS.REC.1394.134).

\section{Results}

The growth rate of cell lines in effect of different concentrations of genistein in three periods of time 24,48 and 72 hours are compared in Figure 2. The growth rate of treated MOLT4 cells declined with the increasing concentrations of genistein. With regard to the concentration of $10 \mu \mathrm{M}$, in comparison to non-treated cells, the growth rate of $100 \%$ was reduced to $75 \%$ on the first day. On the second day, it became $64.4 \%$ and on the third day, it reached $29.4 \%$. For the $25 \mu \mathrm{M}$ concentration, the growth rate in the third day reached $26.47 \%$ (almost the same as $10 \mu \mathrm{M}$ and no significant difference in growth inhibition was observed). Reducing the growth rate in effect of $40 \mu \mathrm{M}$ concentration compared to the non-treated state on the third day became $10.3 \%$. A significant difference $(\mathrm{p}>0.012)$ was calculated in comparison with the growth rate of 10 and $25 \mu \mathrm{M}$. Finally, concentration of $55 \mu \mathrm{M}$ compared to the non-treated state, the cell growth rate in the first, second and third days declined to $22.9,10$ and $5 \%$, respectively (significant reduction as compared to the other three concentrations). Almost the same trend was observed for JURKAT cell line. In comparison with non-treated cells, no significant reduction in growth rate of JURKAT cells was observed in concentrations of 10 and $25 \mu \mathrm{M}$ in the first day, but $35 \%$ and $27 \%$ reduction in rate of cell growth were observed in the first day of treatment with 40 and $50 \mu \mathrm{M}$ genistein, respectively. Growth rate reached $12.5 \%$ and $8.8 \%$ in effect of 40 and $55 \mu \mathrm{M}$ in the third day, respectively. To study the toxic effects of genistein, MTT assay was performed in three different above-mentioned concentrations in periods of 24, 48 and 72 hours. Totally, MOLT 4 cells showed a decrease in the percentage of live cells along with increasing the concentration as well as time of exposure to genistein in comparison with non-treated ones. The same trend was also observed for JURKAT cell lines. 


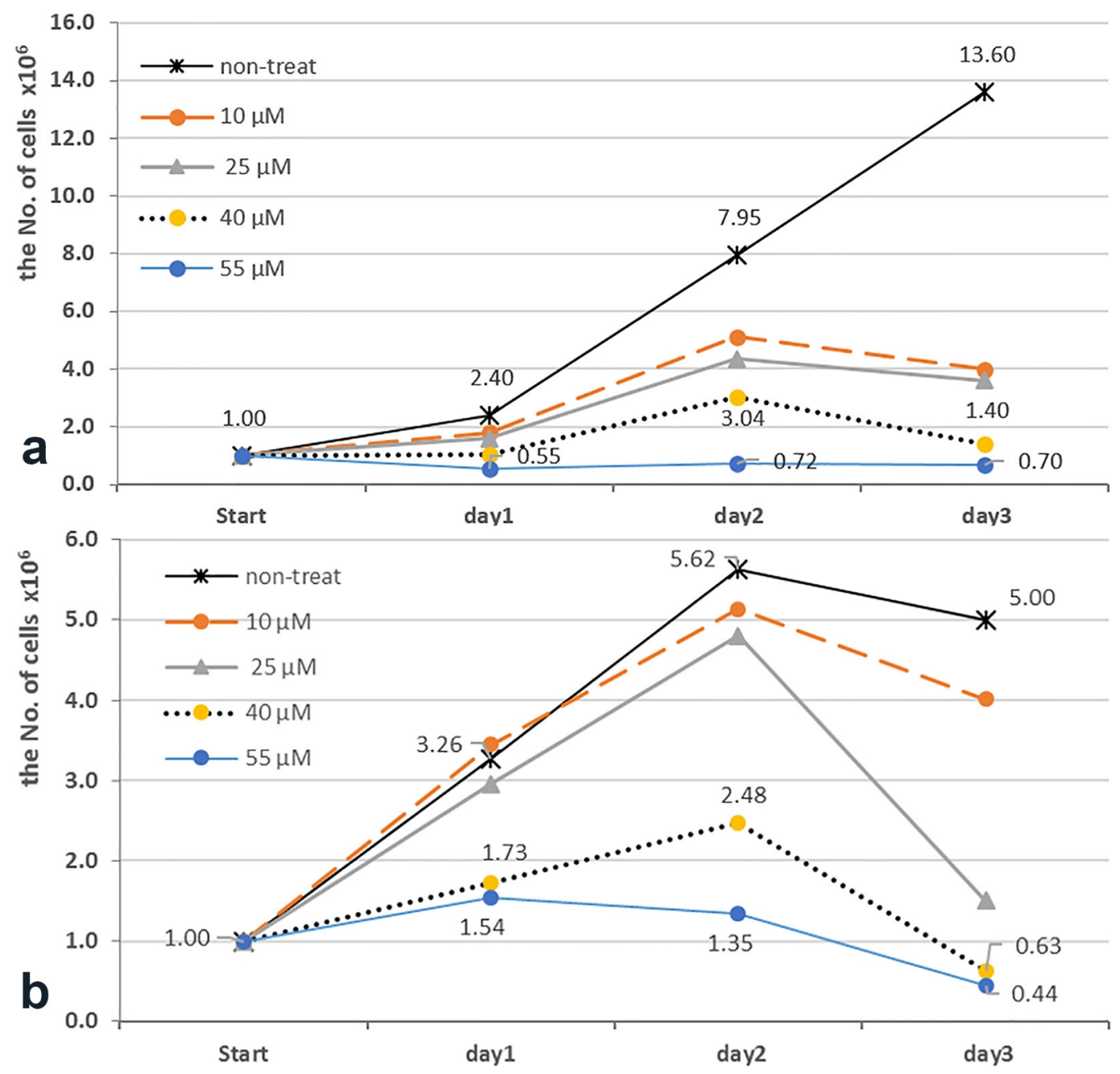

Figure 2. The comparison of growth rate in (a) MOLT4 and (b) JURKAT cell lines under the effect of different concentrations of genistein in three days.

In order to determine the effect of different concentrations of genistein on the expression levels of E-cadherin gene in MOLT4 cell lines, Real-time PCR analysis was performed after 24 and 48 hours. Totally, $10 \mu \mathrm{M}$ genistein could increase the expression level of E-cadherin as compared to the untreated cultures, but not significantly. In the other concentrations (25, 40 and $55 \mu \mathrm{m})$, significant increase was relatively observed. After 48 hours, E-cadherin in treated cultures was significantly up-regulated in all four applied doses ( $\mathrm{p}=0.2$ for $24 \mathrm{hr}$ and $\mathrm{p}=0.028$ for $48 \mathrm{hr}$ ) (Figure 3a). No significant modification in expression level of the E-cadherin gene was observed in JURKAT cells after 24 hours treatment. After 48 hours treatment, JURKAT cells presented a significant up-regulation in a dose-dependent manner ( $\mathrm{p}>0.4$ for $24 \mathrm{hr}$ and $\mathrm{p}=0.0286$ for $48 \mathrm{hr}$ ) (Figure $3 \mathrm{~b}$ ). E-cadherin expression was significantly ( $<<0.02$ ) upregulated between 2 to 4 times in comparison with untreated cells. Overall, expression of E-cadherin after 48 hours treatment by various doses of genistein increased significantly in both MOLT4 and JURKAT cells (Figure 4). 

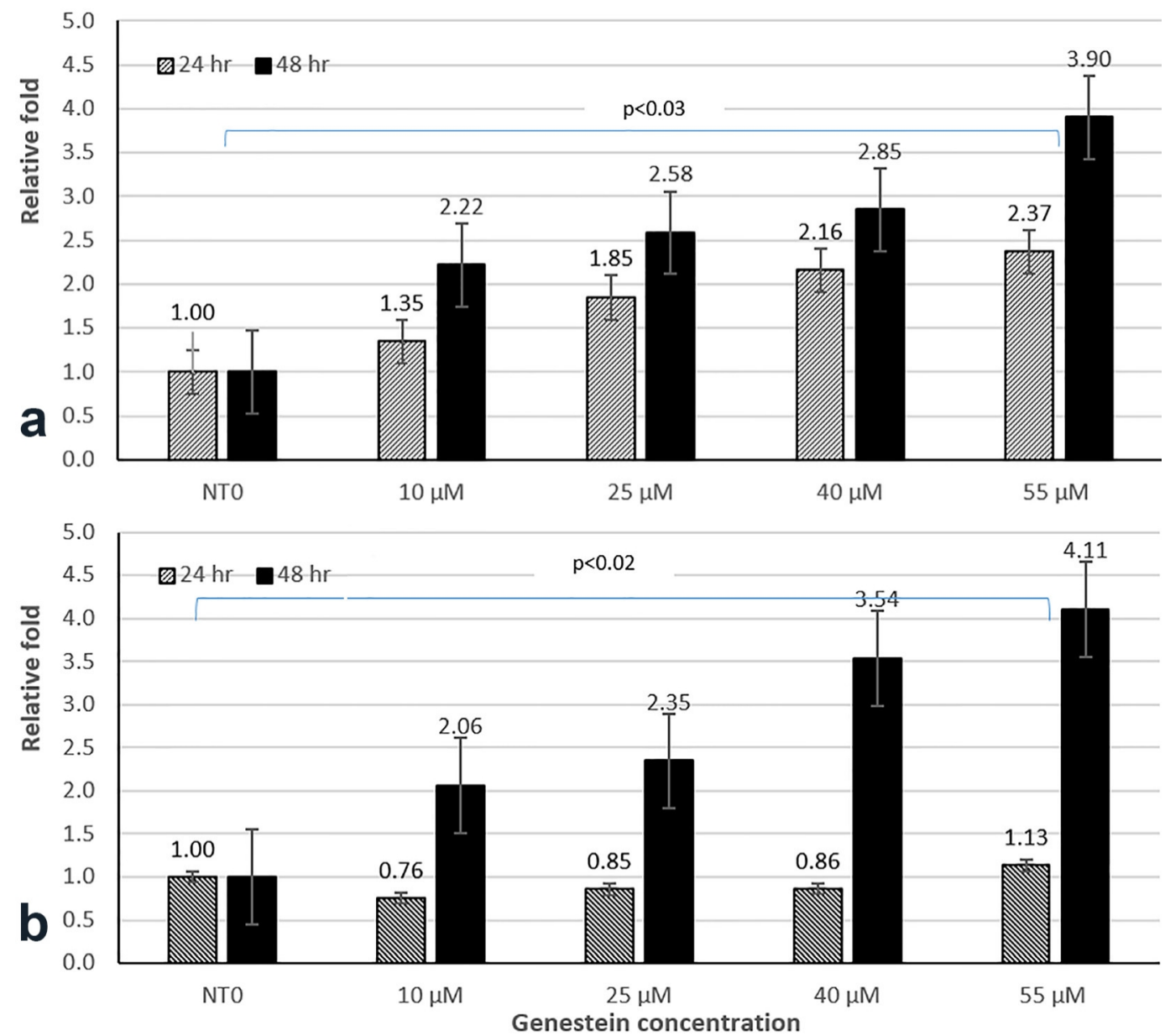

Figure 3. The Comparison the expression of E-cadherin after 24 and $48 \mathrm{hrs}$ treatment with different doses of genistein in (a) MOLT4 ( $\mathrm{p}=0.2$ for $24 \mathrm{hr}$ and $\mathrm{p}=0.028$ for $48 \mathrm{hr}$ ) and (b) JURKAT ( $>0.4$ for $24 \mathrm{hr}$ and $\mathrm{p}=0.0286$ for $48 \mathrm{hr}$ ) ALL cell lines.
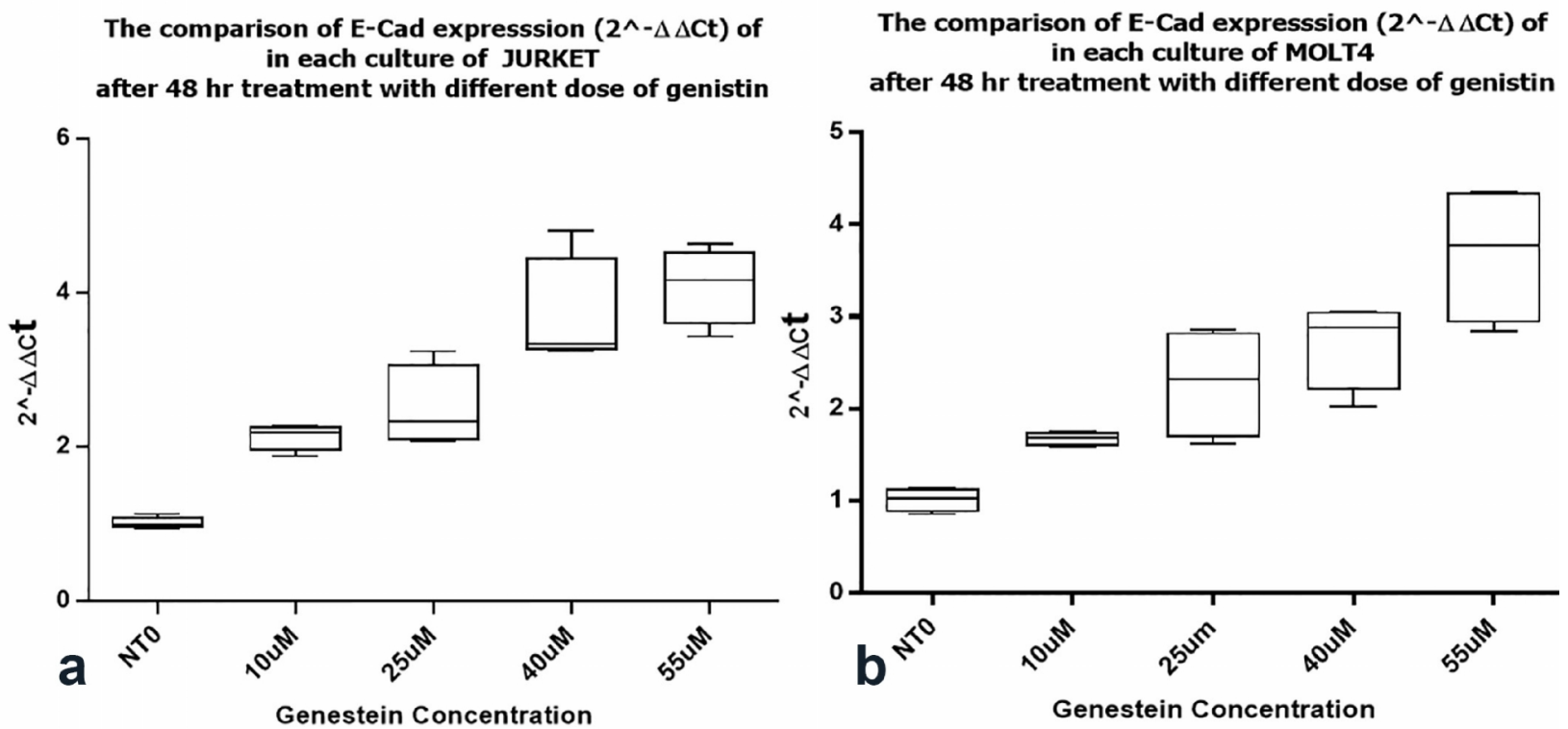

Figure 4. The comparison E-cadherin expression in (a) JURKAT and (b) MOLT4 cell lines after 48 hours' treatment with different doses of genistein. 


\section{Discussion}

Due to increased prevalence of ALL, efforts for finding new and novel therapeutic applications have increased worldwide in recent years. Genistein, which is abundantly found in soybean, is anti-proliferative cancer cell. Genistein is a potent inhibitor of tyrosine kinase, which is involved in proliferation signal cascades of cell growth (5), and moderate doses of genistein have been found to have inhibitory effects on prostate, cervix, brain, breast and colon cancers (7). The inhibitory effects of genistein on carcinogenesis and cancer progression have been known for years. Experimental evidence has revealed that the inhibition of cancer cell growth by genistein is mediated by the modulation of genes associated to the control of cell cycle and apoptosis, invasion, and metastasis. This compound is bioactive, exhibiting anti-inflammatory properties and playing roles in tyrosine kinase inhibition and phytoestrogen and anti-cancer effects (14). The present research examined whether genistein has an inhibitory impact in growth of leukemia cell lines or not. The second question that we tried to answer was whether E-cadherin pathway would be involved in the inhibitory effects of genistein on ALL cell invasion. Li et al. reported the role of genistein in cell growth and apoptosis-related gene expression in breast cancer cells MDA-MB-231. They found upregulation in the expression level of Bax and $\mathrm{p} 21^{\mathrm{WAF} 1}$ and down-regulation of $\mathrm{Bcl} 2$ and $\mathrm{p} 53$ in treated cells with genistein. They showed that apoptotic cell deaths occur by treating cells with genistein, and flow cytometry demonstrated that with longer treatment of genistein, the number of apoptotic cells increased. They conclude that genistein has an inhibitory effect on the growth of MDA-MB-231 breast cancer cells, regulation of the expression of apoptosis-related genes, and induction of apoptosis through a p53-independent pathway. These findings suggest that genistein could be an effective chemopreventive and therapeutic agent against breast cancer (15). Zhang et al. demonstrated that treatment of prostate cancer cells with low-dose genistein could be a strategy for suppressing cell invasion through the reversal of epithelial mesenchymal transition (EMT), which clearly shows the potential use of genistein as a chemopreventive agent for patients with prostate cancer (16). Zhang et al and Parnes et al. showed that genistein displays several biological activities that lead to prostate cancer prevention and it could be considered as a cancer chemopreventive agent $(16,17)$. In addition, some studies suggested genistein with an anti-metastatic activity for prostate cancer and consumption of genistein leads to lower incidence of clinical prostate cancer metastasis (16, 18). Russo et al. and Spagnuolo et al. demonstrated the role of genistein in inhibition of cell growth (in both hormone-dependent and -independent cancer cells) in a dose-dependent manner $(19,20)$. Russo et al. demonstrated that genistein has an anti-proliferative activity in pharmacological doses (higher than $10 \mu \mathrm{M}$ ) and this suggests that genistein might have in vivo anticancer effects (21). Russo et al and Da Silva et al. revealed that genistein directly inhibits Akt and NF-kB pathways (two important pathways in activation of apoptosis) in prostate malignant cells $(21,22)$. Dai et al. investigated the mechanism of action of genistein on hepatocellular carcinoma (HCC) cells. They showed that genistein exhibits antitumor activity through modulating cellular motility and migration (23).

From the available literature on the web, there is no documented study regarding the effect of genistein as a potent growth inhibitor against ALL and it seems that is the first study accomplished. Two ALL cell lines including MOLT4 and JURKAT (respectively as mild and high aggressive acute lymphoblastic leukemia cell lines) were investigated by treatment with different concentrations of genistein $(10,25,40$ and $55 \mu \mathrm{M})$ for 24 and 48 hours in the present study. MTT assay was conducted to obtain the cytotoxic dose of genistein. It found that 40 to $55 \mu \mathrm{M}$ can effectively inhibit the growth of ALL cell lines. Based on MTT assay results, direct proportion between increasing the percentage of apoptosis and increasing dose and exposure time to genistein was obtained. The percentage of vital malignant cells treated with genistein in comparison with non-treated cells was significantly decreased $(p<0.03)$.

High correlation was seen between genistein and reduction of the growth rate in time- and dose-dependent manner, higher concentrations of genistein and longer treatment periods demonstrated more reduction in growth rate. Increasing the time of exposure to a higher non-toxic dose of genistein could effectively induce its anti-proliferative effect against acute lymphoblastic leukemia (5). Of course, reduction in growth rate in 72 hours could be due to the lack of nutrients in the cell. Even though it seems that genistein induces its anti-cancer properties on all doses, strong association found that these anti-cancer properties had a negative correlation with increasing the concentration and exposure time of genistein. Similar to other studies above-mentioned, in the present study, we showed that genistein exhibits growth inhibitory property against leukemia cell lines. In fact, our findings were in line with the findings of other studies in solid tumors.

E-cadherin is a cell-cell adhesion molecule, transmembrane glycoprotein $120-\mathrm{kDa}(11,12)$ involved in mediating cell-cell adhesion between adjacent epithelial cells in various tissues $(12,13)$. This glycoprotein is thought to play a significant role in trophoblastic differentiation. Cellular adhesiveness may be a critical step in the ability of epithelial tumor cells to invade and metastasize both in vitro and in animal model systems (12). This gene is located on chromosome 16 (16q22.1) encodes a protein product important in the maintenance of the epithelial phenotype 
mediated by a Ca-dependent, homotypic cell-cell adhesion (24). Qian Li et al. discovered that lack of E-cadherin gene expression in cancer cells leads to dysfunction of the cell-cell junction system activating cancer invasion and metastasis, therefore, E-cadherin could be an important tumor-suppressor gene (25). Many papers have reported regulation of E-cadherin expression by epigenetic modifications. Aberrant hypermethylation of $\mathrm{CpG}$ islands is a particular mechanism in cancer biology because of a strong association with gene inactivation (18). Although most $\mathrm{CpG}$ dinucleotides in a normal cell have undergone methylation, the $\mathrm{CpG}$ dinucleotides including $\mathrm{CpG}$ islands are essentially unmethylated in all tissues (19), but seem to undergo excessive methylation (hypermethylated), in particular tumor suppressor genes in most malignancies including leukemia. Hypermethylation is a main cause of decreased E-cadherin expression (26). While E-cadherin protein is mostly present in the cell surface of epithelial cells, it has also been accepted that colony-forming units-erythrocytes (CFU-E), normoblasts, and erythroblasts express E-cadherin $(6,7)$. It is definite that erythroid progenitor cells are reliant on E-cadherin gene expression for maturation (24).

Jalali et al. showed that E-cadherin could be a prognostic biomarker for breast cancer. They demonstrated through immunohistochemistry with monoclonal antibodies that increasing the expression levels of E-cadherin has a negative correlation with tumor size, malignancy stage and lymphatic metastasis level (27). Also, Jalali et al. concerning the role of the E-cadherin in prognosis of papillary thyroid carcinoma, revealed that as proportion of Ecadherin decreases in tumor cells, the probability of lymph nodes involvement increases (28). Tsao et al. showed that loss of E-cadherin is associated with progression and poor survival in nasopharyngeal carcinoma (NPC). In this study, the role of methylation on E-cadherin inactivation in NPC cell lines and NPC tissue samples was investigated. Results indicate that 5' $\mathrm{CpG}$ island methylation of the E-cadherin gene are important in the inactivation of E-cadherin in NPC and propose that decreasing the methylation of the E-cadherin gene may be an essential therapeutic strategy for NPC (12). Nishimura et al. indicated that $5^{\prime} \mathrm{CpG}$ island methylation leads to loss of E-cadherin expression, and could indirectly cause the suppression of gap junctional intercellular communication (GJIC) through aberrant localization of connexins (Cxs) in endometrial carcinoma cells (29). Corn et al., showed that 5'CpG island methylation caused silencing the expression of E-cadherin in acute leukemia. They found that methylation was associated with loss of E-cadherin RNA and protein in leukemia cell lines and primary leukemia. Their results revealed the methylation of E-cadherin in acute leukemia and provided a hypothesis for E-cadherin down-regulation in leukemogenesis (30).

\section{Limitations}

In this study, we have some limitations such as lack of normal cells, lack of access to antibodies for determination level of gene expression at the protein level due to the project's financial constraints, and no access to a flow cytometry device for determining the rate of induction of apoptosis in different genistein concentrations.

\section{Conclusions}

In conclusion, this study can be viewed as a pioneering research of its kind to raise another mechanism of action of genistein against ALL cancer cells. The obtained findings could suggest that genistein possesses certain anti-cancer properties in ALL similar to solid tumor cells. From increasing the expression of E-cadherin as a tumor suppressor gene, what it is pioneering in reporting is another mechanism of action of genistein and it can be deduced that this natural isoflavone could be considered as an agent to potentially control the invasion of leukemia cells and expedition of disease, which is promising and fascinating. Our findings suggest that further studies be carried out on effects of genistein on other cell lines and ALL patients. For genistein effects and epigenetic changes including cadherin hypermethylation and evaluation of the combined effect of genistein and other anticancer drugs on cell culture, in vivo and in vitro studies are suggested.

\section{Acknowledgments:}

This work was financially supported by the Research Vice Chancellor of Hormozgan University of Medical Sciences (HUMS); Bandar Abbas; Iran (Project no: 9380) who is gratefully acknowledged.

\section{Conflict of Interest:}

There is no conflict of interest to be declared.

Authors' contributions:

All authors contributed to this project and article equally. All authors read and approved the final manuscript. 


\section{References:}

1) Silverman LB, Sallan SE. Newly diagnosed childhood acute lymphoblastic leukemia: update on prognostic factors and treatment. Curr Opin Hematol. 2003; 10(4): 290-6. PMID: 12799535.

2) Rosenquist R. The role of inflammation autoimmune disease and infectious agents in development of leukaemia and lymphoma. J Intern Med. 2008; 264(6): 512-3. doi: 10.1111/j.1365-2796.2008.02028.x. PMID: 19017175.

3) Paixão VA, Vidal DO, Caballero OL, Vettore AL, Tone LG, Ribeiro KB, et al. Hypermethylation of CpG island in the promoter region of CALCA in acute lymphoblastic leukemia with central nervous system (CNS) infiltration correlates with poorer prognosis. Leuk Res. 2006; 30(7): 891-4. doi: 10.1016/j.leukres.2005.11.016. PMID: 16712930.

4) Tasian SK, Loh ML, Hunger SP. Childhood Acute Lymphoblastic Leukemia: Integrating Genomics Into Therapy. Cancer. 2015; 121(20): 3577-90. doi: 10.1002/cncr.29573. PMID: 26194091.

5) Liu X, Li X, Yin L, Ding J, Jin H, Feng Y. Genistein inhibits placental choriocarcinoma cell line JAR invasion through ERß/MTA3/Snail/E-cadherin pathway. Oncol Lett. 2011; 2(5): 891-897. doi: 10.3892/ol.2011.338. PMID: 22866146, PMCID: PMC3408011.

6) Akiyama T, Ogawara H. Use and Specificity of Genistein as Inhibitor of Protein-Tyrosine Kinases. Methods Enzymol. 1991; 201: 362-70. doi: 10.1016/0076-6879(91)01032-W. PMID: 1658553.

7) Wang $\mathrm{Y}$, Wang $\mathrm{H}$, Zhang $\mathrm{W}$, Shao $\mathrm{C}$, $\mathrm{Xu} \mathrm{P}$, Shi $\mathrm{CH}$, et al. Genistein sensitizes bladder cancer cells to hcpt treatment in vitro and in vivo via atm/nf-kb/ikk pathway-induced apoptosis. PLoS One. 2013; 8(1): e50175. doi: 10.1371/journal.pone.0050175 PMID: 23365634, PMCID: PMC3554754.

8) Li W, Frame LT, Hoo KA, Li Y, D'Cunha N, Cobos E. Genistein inhibited proliferation and induced apoptosis in acute lymphoblastic leukemia, lymphoma and multiple myeloma cells in vitro. Leuk Lymphoma. 2011; 52(12): 2380-90. doi: 10.3109/10428194.2011.598251. PMID: 21749310.

9) Narasimhan K, Lee YM, Lim TK, Port SA, Han JH, Chen CS, et al. Genistein exerts anti-leukemic effects on genetically different acute myeloid leukemia cell lines by inhibiting protein synthesis and cell proliferation while inducing apoptosis - molecular insights from an iTRAQ ${ }^{\mathrm{TM}}$ quantitative proteomics study. Oncoscience. 2015; 2(2): 111-24. PMID: 25859554, PMCID: PMC4381704.

10) Azarova AM, Lin RK, Tsai YC, Liu LF, Lin CP, Lyu YL. Genistein Induces Topoisomerasae IIbeta- and Proteasome- Mediated DNA Sequence Rearrangements: Implications in Infant Leukemia. Biochem Biophys Res Commun. 2010; 399(1): 66-71. doi: 10.1016/j.bbrc.2010.07.043. PMID: 20638367, PMCID: PMC3376163.

11) Whittard JD, Craig SE, Mould AP, Koch A, Pertz O, Engel J, et al. E-cadherin is a ligand for integrin a2b1. Matrix Biol. 2002; 81(5): 525-32. doi: 10.1016/S0945-053X(02)00037-9. PMID: 12392763.

12) Tsao SW, Liu Y, Wang X, Yuen PW, Leung SY, Yuen ST, et al. The association of E-cadherin expression and the methylation status of the E-cadherin gene in nasopharyngeal carcinoma cells. Eur J Cancer. 2003; 39(4): 524-31. PMID: 12751385.

13) Coutifaris C, Kao LC, Sehdev HM, Chin U, Babalola GO, Blaschuk OW, et al. E-cadherin expression during the differentiation of human trophoblasts. Development. 1991; 113(3): 767-77. PMID: 1821848.

14) Shuna Cui, Juan Wang, Qingqing Wu, Jing Qian, Changshui Yang, Ping Bo. Genistein inhibits the growth and regulates the migration and invasion abilities of melanoma cells via the FAK/paxillin and MAPK pathways. Oncotarget. 2017; 21674-91. doi: 10.18632/oncotarget.15535.

15) Li Y, Upadhyay S, Bhuiyan M, Sarkar FH. Induction of apoptosis in breast cancer cells MDA-MB-231 by genistein. Oncogene. 1999; 18(20): 3166-72. doi: 10.1038/sj.onc.1202650. PMID: 10340389.

16) Zhang LL, Li L, Wu DP, Fan JH, Li X, Wu KJ, et al. A novel anti-cancer effect of genistein: reversal of epithelial mesenchymal transition in prostate cancer cells. Acta Pharmacol Sin. 2008; 29(9): 1060-8. doi: 10.1111/j.1745-7254.2008.00831.x. PMID: 18718175.

17) Howard L, Parnes MD, William D, Pharm D. Chemoprevention in Prostate Cancer. Pharmacotherapy. 2006; 57: 1533. doi: 10.1592/phco.26.10.1533.

18) Severson RK, Nomura AM, Grove JS, Stemmermann GN. A Prospective Study of Demographics, Diet, and Prostate Cancer among Men of Japanese Ancestry in Hawaii. Cancer Res. 1989; 49(7): 1857-60. PMID: 2924323.

19) Maria R, Carmela S, Idolo T, Gian Luigi R. Phytochemicals in Cancer Prevention and Therapy: Truth or Dare? Toxins. 2010; 2(4): 517-51. doi: 10.3390/toxins2040517. PMID: 22069598.

20) Carmela S, Gian Luigi R, Ilkay Erdogan O, Solomon H, Maria D, Antoni S, et al. Genistein and Cancer: Current Status, Challenges, and Future Directions. Adv Nutr. 2015; 6(4): 408-19. doi: 10.3945/an.114.008052. PMID: 26178025. 
21) Russo M, Gian Luigi A, Daglia M, DeviKasi P, Ravi S, Nabavi SF, et al. Understanding genistein in cancer: The "good" and the "bad" effects: A review. Food Chem. 2016; 196: 589-600. doi: 10.1016/j.foodchem.2015.09.085. PMID: 26593532.

22) Henrique B, Eduardo P, Eduardo L, Nathalia C, Rodrigo A, Carina C, et al. Dissecting Major Signaling Pathways throughout the Development of Prostate Cancer. Prostate Cancer. 2013; 2013: 23. doi: $10.1155 / 2013 / 920612$.

23) Weiqi D, Lei H, Chunlei L, Shumei W, Ping C, Yan Z, et al. Genistein Inhibits Hepatocellular Carcinoma Cell Migration by Reversing the Epithelial-Mesenchymal Transition: Partial Mediation by the Transcription Factor NFAT1. Mol Carcinog. 2015; 54(4): 301-11. doi: 10.1002/mc.22100. PMID: 24243709.

24) Melki JR, Vincent PC, Brown RD, Clark SJ. Hypermethylation of E-cadherin in leukemia. NEOPLASIA.2000; 3208-13. PMID: 10807790.

25) Qian Li, Hong Chen. Epigenetic modifications of metastasis suppressor genes in colon cancer metastasis. Journal homepage. 2011; 1559-2294. doi: 10.4161/epi.6.7.16314.

26) Liu YN, Lee WW, Wang CY, Chao TH, Chen Y, Chen JH. Regulatory mechanisms controlling human Ecadherin gene expression. Oncogene. 2005; 24(56): 8277-90. doi: 10.1038/sj.onc.1208991. PMID: 16116478.

27) Jalali Nadooshan MR, Davati A, Akhavan F. Expression of E-cadherin in primary breast cancer and and its correlation with prognosis factors. Shahrekord University of Medical Sciences. 2009; 11(3): 55-60.

28) Jalali Nadoushan MR, Davati A, Hassanpour M. Relation between E-cadherin expressions in papillary thyroid carcinoma with some prognostic factors. Quarterly of the Horizon of Medical Sciences. 2014; 19(4): $192-6$.

29) Makoto N, Tsuyoshi S, Hiroshi Y, Ryuichi K. Suppression of gap junctional intercellular communication via $50 \mathrm{CpG}$ island methylation in promoter region of E-cadherin gene in endometrial cancer cells. Carcinogenesis. 2003; 24(10): 1615-23. doi: 10.1093/carcin/bgg121.

30) Corn PG, Smith BD, Ruckdeschel ES, Douglas D, Baylin SB, Herman JG. E-Cadherin Expression Is Silenced by 5'CpG Island Methylation in Acute Leukemia. Clin Cancer Res. 2000; 6(11): 4243-8. PMID: 11106238 . 